Elana R. Anderson

is Vice President of Product

Marketing and Strategy at Unica.

With nearly 20 years of marketing

and technology consulting

experience, Anderson is a highly

regarded marketing software

visionary, who previously served

as Vice President and Research

Director of the marketing practice at Forrester Research. During her tenure at Forrester, Anderson directed the firm's marketing practice and focused on customer marketing strategy, relationship marketing, interactive marketing, customer analytics and marketing technology. Before joining Forrester in 2002, Anderson spent nearly 15 years as a consultant with firms including Andersen Consulting (now Accenture) and Tessera Enterprise Systems. She has been exclusively focused on marketing strategy and technology since 1995, and has led successful marketing strategy and technology implementation projects for Fortune 500 firms in the retail, high-tech and financial services verticals. Anderson shares her insights in her blog at www. nxteramarketing.com.

Keywords: interactive marketing, campaign management, marketing automation, enterprise marketing management, relationship marketing, online marketing, inbound marketing
Elana R. Anderson

Unica Corporation 170 Tracer Lane Waltham, MA 02451, USA Tel: +17814878680 Fax: +1 7818902557 E-mail: eanderson@unica.com

\section{Next-generation campaign management: How campaign management will evolve to enable interactive marketing}

\author{
Elana R. Anderson \\ Received: 25 November 2008
}

\begin{abstract}
This paper explains how marketers must redefine their approach to reflect radical shifts in channels and customer behaviour - including an accelerating shift toward addressability, growing convergence between online and direct channels, and increasing customer power to shape marketing dialogues and buying experiences. The author discusses how marketers must engage customers and prospects in a personal, cross-channel conversation that builds upon that individual's past and current behaviour. She also explains how marketers must listen to all information provided, analyse it and respond - sometimes in real-time - in ways that are compelling, timely and relevant. Finally, the author discusses the fundamentally new marketing tools, stronger integration and revamped organisational structure that will be required to achieve these goals. Journal of Direct, Data and Digital Marketing Practice (2009) 10, 272-282. doi:10.1057/dddmp.2008.46
\end{abstract}

\section{Three shifts have fundamentally changed marketing}

Most marketers recognise that their discipline is in a period of rapid change. Unfortunately, many are responding by simply trying to do more of what they have already been doing: shouting out their messages as broadly and loudly as possible. As marketers turn up the volume, buyers are simply tuning out. In many companies, this is leading to diminishing returns: marketing costs are rising while returns are declining. It is time to step back, understand the implications of the changes that are occurring and redefine the discipline of marketing accordingly. Although some marketers view these changes as a threat, those who understand them can gain significant competitive advantage.

In this paper, we review the shifts in channels, customer behaviour and technology that are driving the need to reinvent marketing. Next, we outline a coherent and unified response, built around interactivity and addressability: the ability to engage customers in a two-way dialogue that builds upon past behaviour, and adapts based on current behaviour, context and each customer's reaction to each new message. Finally, we present the characteristics of the marketing application 
software that are essential to success with this fundamentally new approach to marketing.

\section{Shift 1: The rapid evolution of marketing channels}

For years, marketers have recognised a reasonably well-defined typology of marketing channels. Mass media channels provided access to a wide audience, enabling marketers to quickly maximise exposure to their brands, products and services. Conversely, direct channels such as direct mail, telemarketing or face-to-face communications allowed marketers to communicate with customers individually. With the internet, of course, this simple model has become less and less useful. To begin with, online channels represent a new hybrid, with both mass and direct characteristics. Even as marketers have begun to understand how to utilise tools such as websites, banner ads and e-mail, the online 'centre of gravity' has shifted to search, social networking and other emerging Web 2.0 channels. Specifically,

- Mass media channels have lost their reach: Events such as the Olympics or the Super Bowl, which still reach enormous mass audiences, have become an ever-rarer exception. As the availability of content has grown, the mass audience has virtually disappeared. At the same time, as consumers flock to more personalised media, they are becoming increasingly resistant to conventional mass advertising — and they are tuning it out, often using Digital Video Recorders and other technologies to do so.

- Direct channels require more sophistication and integration: Buffeted by growing clutter and buyer fatigue, outbound direct channels such as direct mail, telemarketing and e-mail are suffering from declining response. Entirely new, but also highly personal, direct channels - such as marketing through mobile devices or targeted marketing communications in inbound customer channels including websites, customer service call centres and even ATMs or other points of sale - are also emerging. ${ }^{1}$ For both old and new direct channels, the solution is the same: traditional marketing tactics must give way to communication tactics that leverage customer information to support event-triggered, inbound, real-time, multistage and multichannel interactions.

- Online channels are growing up fast: The internet is no longer 'new media'. Seventy to 80 per cent of consumers in North America and Western Europe are online, and 88 per cent of online users in North America have purchased online. ${ }^{2}$ Online channels are also continuing to evolve, widen and gain in richness and 'sociality', threatening the power and control that companies have traditionally maintained over their message and brand.

\section{Shift 2: Increasing addressability in all channels}

In addition to the fundamental changes occurring in each individual area, marketing channels are also converging in one crucial respect. 
Specifically, more and more channels are becoming, or will become, addressable. The benefit to marketers? Addressable channels support targeted - even individualised - communication.

- Internet channels provide nearly universal addressability: Most sites can address consumers either personally by name, or individually by cookie. Behavioural and contextual targeting techniques are proven and widespread, and direct customer targeting through media sites will become increasingly commonplace as infrastructures improve. Search sites capture detailed personalised information for both contextual and individual ad targeting. In addition, subscription-based online channels such as podcasts are inherently addressable, wherever they happen to be.

- Conventional mass media is becoming increasingly addressable: A print copy of The Financial Times has limited addressability, but online the same content delivered to a customer logged in on ft.com is highly addressable. Even stubbornly 'mass' channels are becoming more addressable. The US cable industry's Project Canoe is developing advanced set-top boxes to enable individually targeted ads based on taste and lifestyle. ${ }^{3,4}$ In a recent test, the Mini Cooper placed Radio Frequency Identification chips in selected key fobs, which were then read by digital billboards to display targeted messages as individuals drove by. ${ }^{5}$ Advertisers are placing 'Quick Response Codes' on billboards that users can scan with their mobile devices, thereby delivering more detailed content to the mobile device. ${ }^{6}$ Finally, supermarkets are trialing shopping carts linked to customer loyalty card databases, with LCDs that show customised advertising to individual shoppers based on their previous purchases. ${ }^{7}$

\section{Shift 3: Empowered customers, behaving in fundamentally new ways}

As marketers well know, customers have changed radically in the past decade, and all these changes reinforce one central reality: yesterday's 'batch-and-blast', 'push' marketing strategies no longer work.

- Customers have taken control over the relationship and flow of information: The internet has given customers unprecedented access to third-party information and opinions about your company, your offerings, your marketing claims, your service and often even your pricing. They can identify and leverage competitive alternatives that were once inaccessible. They are even gaining more control over how you contact them - and they can increasingly evade unwanted messages.

- Customers can now shape your brand: Whether you like it or not, customers now have a powerful 'soapbox' they can use to shape your brand. Universal McCann reports that 34 per cent of active internet users post opinions about products and brands on their blogs. ${ }^{8}$ Some rave, but many more of them are raging at the customer service and marketing they encounter. 
- Customers feel free to choose among — and move among channels: Customers feel completely free to choose among channels - and to move among channels at will. 'Multi-channel retail' - purchases made after a shopping experience that encompasses online and offline channels - will be worth \$1.2trillion by $2012 .{ }^{9}$ In a recent survey, among consumers who made a considered purchase, 67 per cent engaged with the web at some point during their research process. ${ }^{10}$ For commodity purchases, consumers may buy online one day and in your store the next, based on whatever is more convenient. In such an environment, it is not enough to simply deliver consistent messages across channels; you need strong cross-channel awareness of how each individual customer has responded (or failed to respond) in the past.

\section{Marketing must be more interactive}

The three shifts are systemic. They span all geographies and types of business. They will not be reversed or slowed. The question is: how can marketers best respond?

Forward-looking marketers recognise that they need new skills to effectively engage, communicate and interact with today's customers. Specifically, marketing organisations realise they must retool their organisations in order to

- listen to all the information provided by customers and prospects - both explicit and implicit;

- understand past and present information to determine the best possible marketing action;

- communicate in a manner that is compelling, timely and relevant.

Moreover, marketers must be able to do all this across all inbound and outbound channels - and do so in an integrated way.

\section{Interactive marketing: Tomorrow's dominant marketing discipline}

Marketers that successfully adopt and integrate all these capabilities will fundamentally change the marketing discipline. This new form of marketing deserves its own name: interactive marketing. The term is not new: John A. Deighton of the Harvard Business School coined it some 15 years ago. ${ }^{11}$ Two things have changed, however. First, implementing interactive marketing has become a business necessity. Secondly, doing so is now more realistic for the vast majority of marketers.

Interactive Marketing: Engaging each customer and prospect in a cross-channel dialogue that builds upon his or her past and current behaviour. $^{12}$

The transition to interactive marketing requires marketing organisations to evolve by shifting communication strategies and tactics away from one-size-fits-all push marketing to a more customer-centric approach 
that leverages the increasing availability of addressable channels and strives for responsiveness to individual customer behaviours. Specifically, this means abandoning the old-style push marketing campaign construct and adopting new marketing tactics that

- react to customer inputs or changes in behaviour;

- identify the best treatment strategy in real-time, based on knowledge of the customer and the context of the inbound interaction;

- link discrete interactions into a dialogue that lasts over time;

- cross channels, and carry the dialogue forward by leveraging a memory of the conversation and the context of the current interaction.

\section{Interactive marketing in action: Three snapshots}

Let us consider some examples of interactive marketing in the real world. In each case, the customer benefits from a seamless, integrated experience that cuts across channels - and the marketer can guide each individual customer to a buying decision more rapidly and effectively.

\section{Interactive marketing in online retail}

In the first scenario, an online retailer has identified two business challenges: recapturing abandoned shopping carts and driving related impulse purchases. When a customer visits the site's home page, she is invited to view customised offers based on her earlier behaviour. If she places items in her shopping cart, and then abandons a transaction, a follow-up e-mail is sent the following day, containing customised offers in the same category as the items she abandoned (Figure 1).

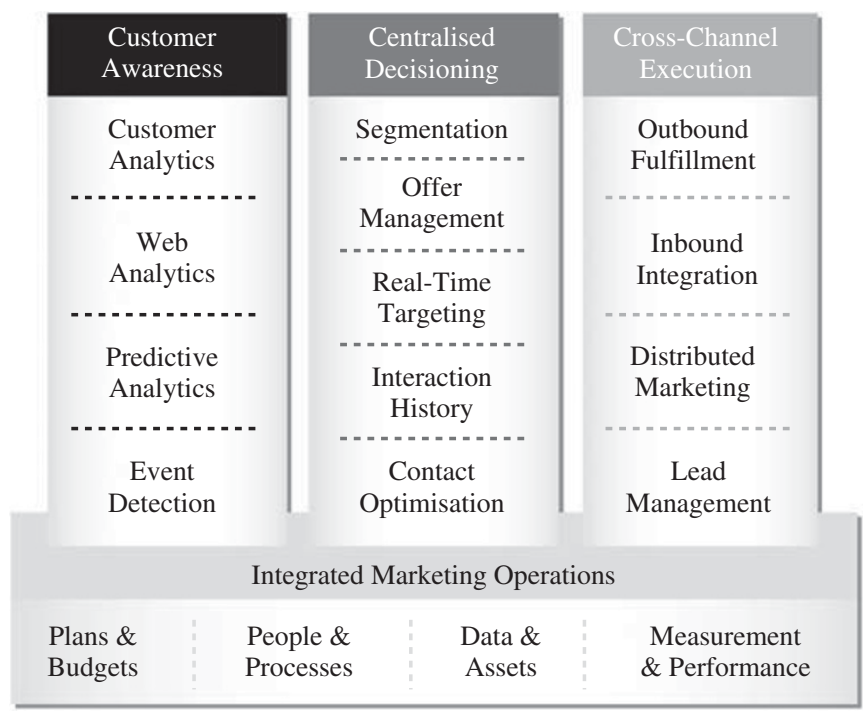

Figure 1: Interactive marketing in online retail 


\section{Interactive marketing in banking}

In this second scenario, a bank needs to cross-sell more effectively, and market more consistently across all of its customer touchpoints. When a customer visits the bank's site to check account status, a personalised offer is presented. The customer may view the offer's details, but is unlikely to accept without speaking to a representative. When the customer calls the bank's call centre, the agent sees the offer the customer has already viewed, and can move forward immediately (Figure 2).

\section{Interactive marketing in telecommunications}

Finally, in this third scenario, a telecommunications service provider wishes to reduce costly customer churn. When a customer visits the provider's website to review service plans, he is immediately recognised as a high-value customer whose current plan will expire soon. A premium service renewal offer is presented. When the customer does not respond within two weeks, he receives a follow-up e-mail about the offer. Soon thereafter, the customer receives a text message containing another renewal offer (Figure 3).

\section{Next-generation campaign management is required to execute}

Although each of these scenarios may sound quite simple, from the marketer's standpoint they often introduce unprecedented complexity - requiring several software applications, complex software integration work and significant IT support. In order for marketers to successfully transition to interactive marketing, they need technologies that enable them to interact across inbound as well as outbound channels in an integrated way.

Channel-centric marketing solutions that are difficult to integrate simply cannot achieve the interactivity that is required as customers

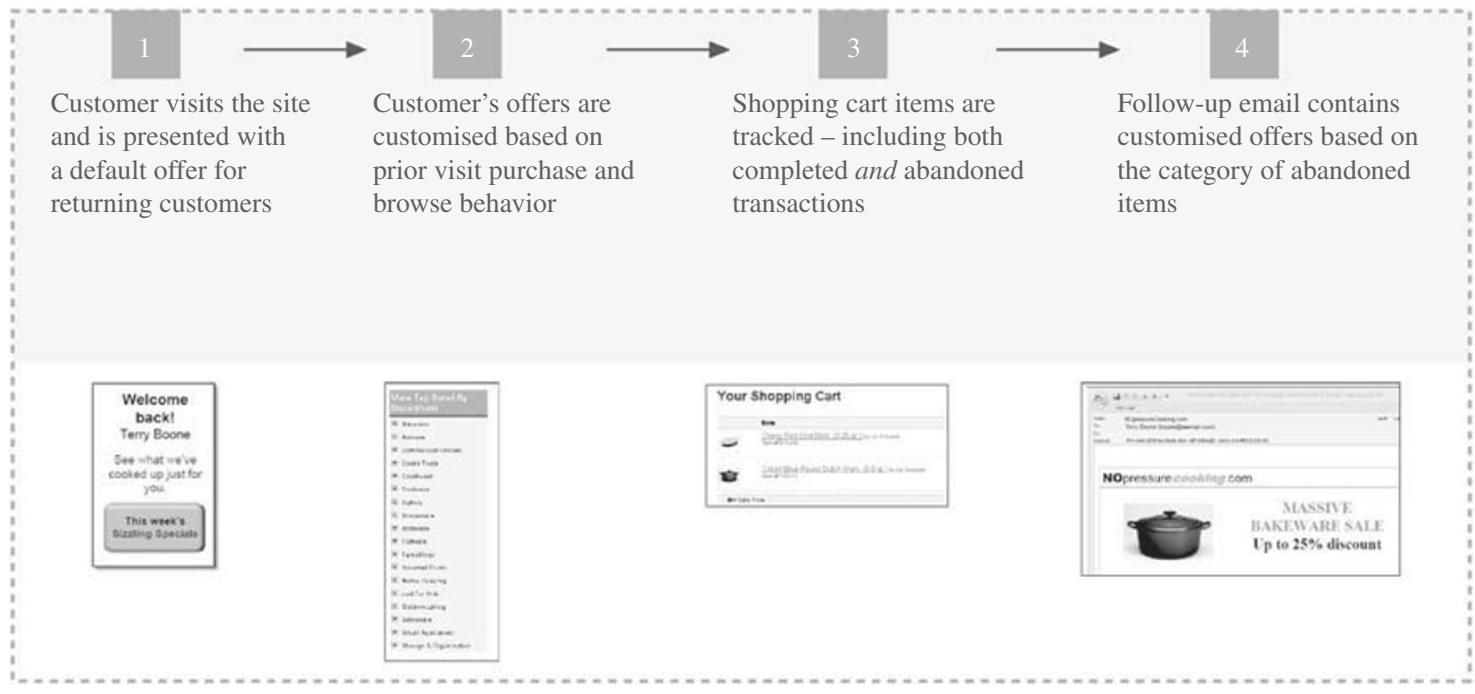

Figure 2: Interactive marketing in banking 
traverse channels. Furthermore, most traditional campaign management solutions were designed to support only traditional outbound marketing. Campaign management is no longer simply about push marketing, segmentation and list pull, and outbound channels only. To support marketing needs today and in the future, campaign management and marketing automation solutions must evolve (Figure 4).

The next generation of campaign management technologies must

- be customer-aware;

- support centralised decision-making;

- enable cross-channel execution;

— integrate marketing operations.

\section{Customer awareness}

The key to listening is the ability to capture what a buyer is saying both explicitly and implicitly — and to process that information to determine what to say next. This requires a technology solution that can leverage and process both a customer's history and present situation, to identify actionable customer insights, alert marketers to

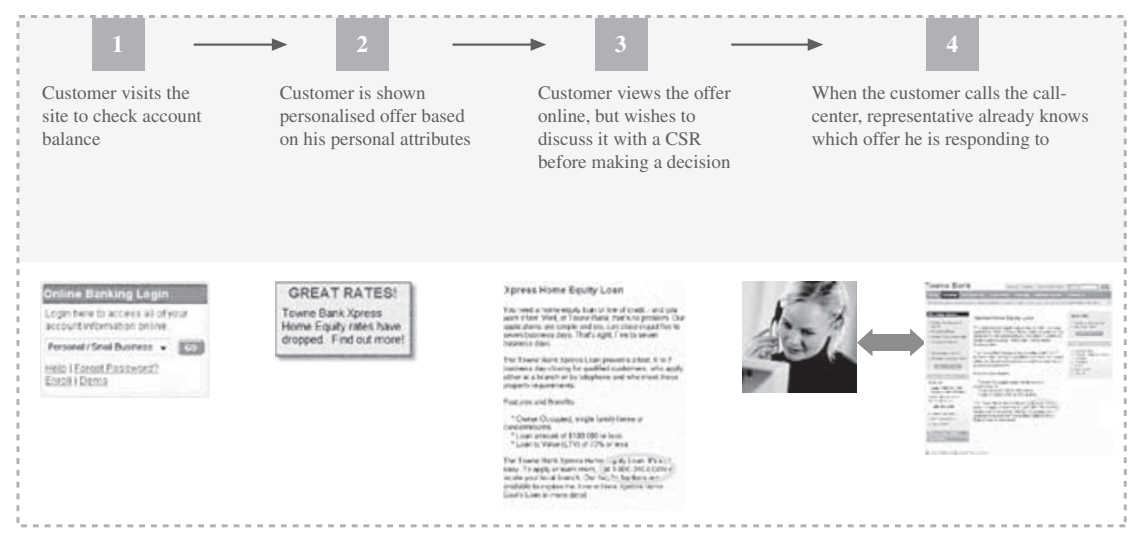

Figure 3: Interactive marketing in telecommunications

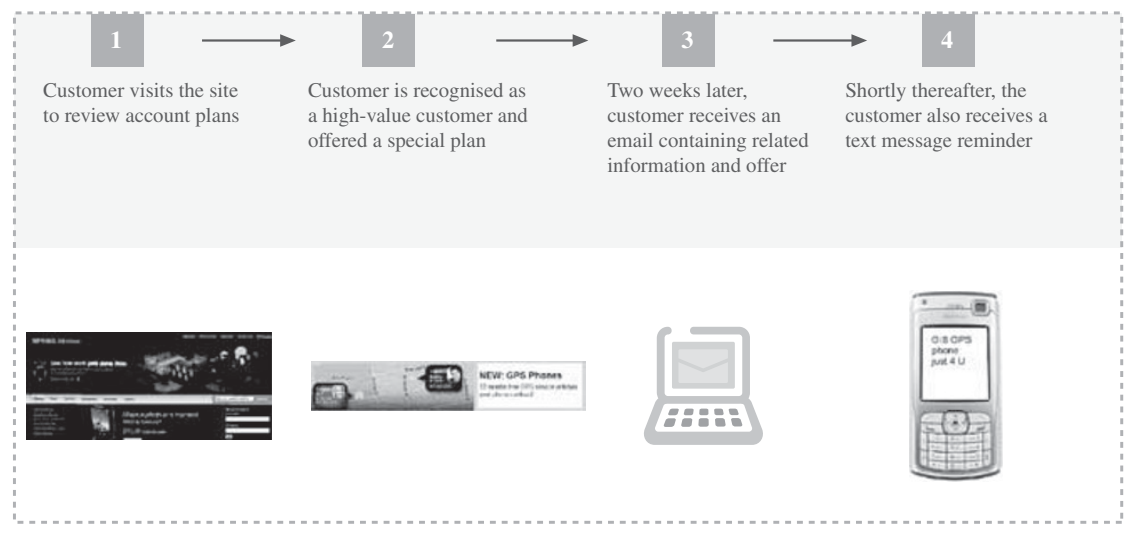

Figure 4: Next-generation campaign management 
potential customer opportunities and predict marketing outcomes. To make this happen, next-generation campaign management solutions must provide

- customer analytics that give marketers visual, graphical analysis of customer data, simplify the creation of customer groups and segments and enable marketers to quickly transform information into action, without programming or technical support;

- web analytics that draw on customer historical profile data and offline transactions, simplify the evaluation of web marketing effectiveness and help uncover customers' unspoken intentions;

- predictive analytics that simplify market segmentation, response prediction, projections of cross-sell and lifetime value, and strategy planning;

- event detection to monitor each customer's transactional behaviour and set off triggers whenever meaningful changes occur.

\section{Centralised decisioning}

Imagine a conversation in which one party cannot hear or understand what the other is saying. Such a conversation would be a disaster for both parties. But, in many respects, this is precisely the kind of conversation most marketers have with their customers. Shifting to interactive marketing means capturing what your customer says to you - as well as how he or she responds to what you say. Within the context of next-generation campaign management, this means establishing a centralised decision-making capability that determines the best marketing message to extend in outbound and inbound marketing channels, both online and offline. To enable centralised decisioning, nextgeneration campaign management solutions must provide

- segmentation capabilities to group customers by like characteristics or behaviour, in order to treat them - and communicate with them - in the most appropriate way;

- offer management to define and manage cross-channel offers in a single repository and automatically identify the best marketing message to extend via any inbound or outbound channel;

- real-time targeting, combining dynamic segmentation logic with real-time learning algorithms and arbitration rules to optimise customer messages in real-time channels;

- interaction history that creates a two-way memory of every marketing message and the customer's reaction to that message;

- contact optimisation designed to help manage marketing communications over time against business objectives and resource constraints.

\section{Cross-channel execution}

Your buyers interact with you across multiple channels. They expect both a consistent and seamless experience as they move between those 
channels. Anyone who has ever been involved with a customer experience initiative knows how challenging it can be to solve this problem. Next-generation campaign management solutions offer indispensable help, by simplifying cross-channel (inbound/outbound, online/offline) execution, and by helping the organisation compile comprehensive marketing communication and response histories. Using these capabilities, companies can drive message and treatment consistency and provide the seamless experience customers demand when they interact with the enterprise. Specifically, next-generation campaign management should support cross-channel execution by providing

- outbound fulfilment tools that support list creation for delivering mail-ready files to letter shops and fulfilment houses, high-volume email execution, and smooth integration with third-party vendors for fulfiling to any outbound channel;

- inbound fulfilment tools that capture real-time contextual information from websites, call centre reps and kiosks, and forward offers to be presented immediately during a current interactive session;

- distributed marketing tools that provide campaign execution capabilities to store/branch managers and other field marketers, enabling them to take advantage of their closeness to the customer, within the framework and rules set by your central marketing organisation;

- lead and response management tools that can capture, score and rapidly route leads and responses to marketing contacts.

\section{Integrated marketing operations}

In typical mid-sized or large companies, making interactive marketing work requires you to manage multiple 'moving parts', and collaborate smoothly across many disparate groups throughout the marketing organisation. To ease these challenges, next-generation campaign management must help marketers improve collaboration and facilitate cross-channel planning, design, execution and measurement. In particular, next-generation campaign management must incorporate

- centralised planning and budgeting that provides universal visibility, top-down budget allocations and full tracking of forecasts and expenses;

- comprehensive process management tools, including master marketing calendars to track programmes and maximise their visibility, as well as tools for assessing resource availability, assigning jobs and tasks, driving project schedules and managing reviews;

- asset and data management tools that capture reusable information and work, simplify management of project and campaign data and provide secure access to all creative assets; 
- performance management tools such as dashboards that make it easy for management to track performance, troubleshoot problems and identify emerging trends in time to leverage them.

\section{Conclusion: What to do now}

In this paper, we have outlined what marketing should come to look like in most organisations. Getting there is, of course, a journey that is neither easy nor instantaneous. This paper has focused on marketing technology that can enable the transition. But technology is not a silver bullet: marketing organisations must also reorganise and retool, rethink their processes and implement metrics based on their new goals. We recommend starting with these four steps:

1. Inventory your internal organisation to identify skill gaps: To succeed in interactive marketing, your organisation needs strong skills in database marketing and management, modelling, online marketing, web analytics and many other areas. In some cases, these skills may exist within your organisation; in other cases, they may need to be purchased or 'grown'. Assess what you have, what you need and where you can find it.

2. Define how your organisation will support interactive marketing: Interactive marketing requires the entire marketing organisation to work together seamlessly. Today, in many marketing organisations, crucial functions such as database and online marketing are siloed - with little contact, and little incentive to cooperate. Some organisations will decide to thoroughly integrate their existing online and offline marketing resources, beginning with crosstraining and cross-functional pilot projects. Others will retain current structures, but revise metrics and incentives to promote cross-functional collaboration instead of retarding it.

3. Consider creating a skunk works team: In many organisations, earlier customer-related initiatives such as CRM only succeeded when they were assigned to small 'skunk works' teams that were given a clean slate and authority to work on their own while the rest of the organisation stayed focused on its day-to-day business. The same may well be true for your interactive marketing initiative.

4. Identify and pursue low-hanging fruit: Although building interactivity into all your marketing efforts is no small task, you can identify discrete projects where a small team can quickly demonstrate value. Be realistic and clear about these projects' business objectives, identify specific metrics you will use and put tools in place to capture them.

Every marketing organisation is different - culturally, structurally and in terms of the customers it serves. There is no single roadmap for getting where you need to go. The point is to set a goal that can drive your planning and priorities. That goal is clear: to create an interactive marketing organisation that can sense virtually all your customer 
opportunities, then deliver the most compelling message to each customer, at the right time, in the most effective channel.

\section{References and Notes}

1. BAI Research. 'Personalizing the remote channels', Banking Strategies, November/December 2007, http://www.bai.org/bankingstrategies/2007-nov-dec/remote_channels/.

2. Forrester Research. 'US eCommerce: 2008 To 2012', Forrester Research, 6th May, 2008.

3. Friedman, W. (2008) 'Addressable TV marketing arrives: Advanced cable boxes to yield customizable ads', Variety, 2nd May, 2008.

4. Early results are promising. According to BrandWeek, testing by Comcast Spotlight and Starcom MediaVest Group (SMG) indicates 'homes receiving addressable advertising tuned away from those ads 38 less than those without it.'

5. New York Times. 'Billboards that know you by name', The New York Times, 29th January, 2007.

6. Golson, J. (2008) 'QR codes: The next CueCat, or destined for U.S. success?' The Industry Standard, 5th September, 2008.

7. Press Media Wire. 'MediaCart, Microsoft and Wakefern team up to deliver next-generation digital grocery shopping and ad experience', Press Media Wire, 14th January, 2008.

8. 'Power to the people: Social media tracker, wave.3', Universal McCann, March 2008.

9. Forrester Research. 'How consumers actually shop for retail products across channels', Forrester Research, 9th May, 2008.

10. Ibid.

11. Deighton, J. A. and Blattberg, R. C. (1991) 'Interactive marketing: Exploiting the age of addressability', MIT Sloan Management Review, Fall, Harvard Business Review.

12. In 1996, Harvard's John Deighton defined interactive marketing as 'the ability to address the customer, remember what the customer says and address the customer again in a way that illustrates that we remember what the customer has told us'. When Deighton originally coined the term, the internet was not a marketing force; Deighton's primary emphasis was using databases to personalise individual customer relationships. Since Deighton originally defined the term, many agencies have positioned themselves as 'interactive marketers', using this term essentially as a synonym for 'online marketers'. The definition proposed here returns to Deighton's original intent, while also including the internet channels which have exploded since he published his original article on the subject. 